\title{
ГЕМОДИНАМИЧЕСКИЕ ПОКАЗАТЕЛИ И ЭЛЕКТРИЧЕСКАЯ АКТИВНОСТЬ СЕРДЦА У ЮНЫХ ТХЭКВОНДИСТОВ РЕСПУБЛИКИ КОМИ В РАЗНЫЕ СЕЗОНЫ ГОДА
}

\author{
Шевелёва Е.С. ${ }^{1}$, Пантелеева Н.И. ${ }^{1}$, Рощевская И.М. ${ }^{1,2}$ \\ ${ }^{1}$ Федеральное государственное бюджетное учреждение науки Федеральный \\ исследовательский центр «Коми научныий центр Уральского отделения Российской \\ академии наук» (ФИЦ Коми НЦ УрО РАН), Россия, Республика Коми, г. Сыктывкар, \\ ${ }^{2}$ Федеральное государственное бюджетное образовательное учреждение выстего \\ образования «Сыктывкарский государственный университет им. Питирима Сорокина» \\ Россия, Республика Коми, г. Сыктывкар, \\ bdr13@mail.ru, compcard@mail.ru
}

\begin{abstract}
Аннотация. У юных тхэквондистов 9-12 лет, проживающих в разных климатических зонах Республики Коми (62 ${ }^{\circ}$ и $67^{\circ}$ с. ш.), исследована электрическая активность сердиа и показатели системной гемодинамики в весенне-летний и зимний период при восстановлении после субмаксимальной физической нагрузки. У юных тхэквондистов субарктической климатической зоны по сравнению со спортсменами, проживающими в умеренном климате, в зимнее время выявлена более неблагоприятная динамика функиионирования сердечнососудистой системы на физическую нагрузку, чем в весенне-летний период. Материалы. Исследование реакции сердечно-сосудистой системы юных тхэквондистов г. Сыктывкара и 2. Воркуты на физическую нагрузку в наиболее и наименее благоприятные сезоны года. Методы исследования: электрокардиография $u$ мониторирование АД $u$ ЧСС при проведении велоэргометрии. Результаты. Выявлены более высокие показатели САД и ДАД у воркутинских тхэквондистов в весенне-летнее время по сравнению с таковыми сыктывкарских спортсменов. Провокация ступенчато возрастающей нагрузкой показала различие показателей электрической активности сердиза у юных тхэквондистов, прожсиваюших в разных климатогеографических зонах Республики Коми. Заключение. Показано, что в весенне-летнее время гемодинамическая реакция на велоэргометрическую функииональную пробу была более неблагоприятной у детей арктической зоны, чем у детей умеренно-континентального климата, что указывает на повышенное напряжение компенсаторных механизмов организма на поддержание гомеостаза в условиях экстремальных природных факторов.
\end{abstract}

Ключевые слова: электрическая активность сердиа, электрокардиограмма, ЧСС, артериальное давление, тхэквондистьл.

Для цитирования: Шевелёва Е.С., Пантелеева Н.И., Рощевская И.М. Гемодинамические показатели и электрическая активность сердца у юных тхэквондистов Республики Коми в разные сезоны года. Педагогико-психологические и медико-биологические проблемь физической культуры и спорта. 2018; 13(3): 208-214. DOI 10.14526/2070-4798-2018-13-3207-213.

\section{HEMODYNAMIC INDICES AND HEART ELECTRICAL ACTIVITY AMONG YOUNG TAEKWONDO ATHLETES OF THE KOMI REPUBLIC IN DIFFERENT SEASONS}

\author{
Sheveleva E.S. ${ }^{1}$, Panteleeva N.I. ${ }^{1}$, Roshchevskaya I.M. ${ }^{1,2}$ \\ ${ }^{1}$ Federal State Budgetary Science Establishment Federal Research Center "Komi Scientific Center \\ of the Ural Department of the Russian Academy of Sciences", Syktyvkar (FRC Komi SC UrD RAS)
}




\section{${ }^{2}$ Federal State Budgetary Educational Establishment of Higher Education «Syktyvkar State University named after Pitirim Sorokin» Syktyvkar, the Republic of Komi bdr13@mail.ru, compcard@mail.ru}

Annotation. Heart electrical activity and the indices of system hemodynamics among 9-12 year-old taekwondo athletes, who live in different climate zones of the Komi Republic $\left(62^{\circ}\right.$ u $67^{\circ}$ c. u. $)$, during spring-summer and winter periods in terms of rehabilitation after submaximal physical load was studied. Young taekwondo athletes of subarctic climate zone, in comparison with athletes, who live in temperate climate, have less favorable dynamics reaction of cardiovascular system to physical load during winter, than during spring-summer period. Material. Studying young taekwondo athletes' (Syktyvkar and Vorkuta) cardiovascular system reaction to physical load in least and most favorable seasons. Research methods: electrocardiography and blood pressure $(B P)$ and heart rate (HR) monitoring during bicycle ergometry. Result. The highest systolic blood pressure $(S B P)$ and diastolic blood pressure $(D B P)$ indices among taekwondo athletes from Varkuta were revealed during spring-summer period in comparison with the same indices of athletes from Syktyvkar. Step-by-step increasing load showed the difference of heart electrical activity indices among young taekwondo athletes, who live in different climatic-geographical zones of the Komi Republic. Conclusion. It is demonstrated that during spring-summer period hemodynamic reaction to bicycle ergometric functional test was more unfavorable among children of the arctic zone, than among children of the moderate-continental climate and it proves increased tension of an organism compensatory mechanisms for homeostasis support in terms of extreme natural factors.

Keywords: heart electrical activity, electrocardiogram, heart rate (HR), blood pressure, taekwondo athletes.

For quotation: Sheveleva E.S., Panteleeva N.I., Roshchevskaya I.M. Hemodynamic indices and heart electrical activity among young taekwondo athletes of the Komi Republic during different seasons. The Russian Journal of Physical Education and Sport. (Pedagogical-Psychological and Medico- Biological Problems of Physical Culture and Sports). 2018; 13(3): 208-214. DOI 10.14526/2070-4798-2018-13-3-207-213.

\section{ВВЕДЕНИЕ}

Большая протяженность зоны Европейского Севера обусловливает различие природных и климатических факторов (атмосферное давление, низкие температуры, продолжительность светового дня, электромагнитный и радиационный фон, ветровая нагрузка) в его отдельных областях, определяет выраженность их действия на организм человека, влияя прежде всего на хронобиологические процессы в организме $[1,2]$. На детский организм, в котором по мере взросления идут непрерывные анатомические и функциональные перестройки, экстремальные экологические воздействия оказывают дополнительное неблагоприятное действие $[3,4]$. При приближении к Северному полюсу степень неблагоприятствия факторов внешней среды нарастает, и даже разница по месту жительства в три градуса по широте в северном направлении приводит к значимым изменениям в работе кардиореспираторной системы подростков - снижению резистентности к кислородному голоданию, замедлению восстановления после физических нагрузок [4]. Однако считают, что у юных спортсменов-северян такие изменения выражены в меньшей степени, чем у не занимающихся спортом детей, так как спортивная деятельность приводит к экономизации работы сердца и нормализации артериального давления, нивелирует характерные пубертатные «скачки» [5]. Морфологические, структурные и функциональные изменения работы сердца растущего организма отражаются на электрической активности 
миокарда, и ее оценка является одной из важнейших задач возрастной физиологии.

Целью данного исследования является изучение реакции сердечнососудистой системы на физическую нагрузку у юных тхэквондистов, проживающих и тренирующихся в условиях разных климатических зон Республики Коми в зимнее и весеннелетнее время.

\section{МАТЕРИАЛЫ И МЕТОДЫ}

Проведено исследование сердечнососудистой системы юных тхэквондистов 9-12 лет, проживающих в г. Сыктывкаре, (масса тела - 39,8 $\pm 2,6$ кг, длина тела $149 \pm 4$ см, n=22); и в г. Воркуте (масса $40,7 \pm 3,6$ кг, длина тела $-146 \pm 3 \mathrm{~cm}, \mathrm{n}=18)$. Тренировочная нагрузка по занятиям тхэквондо составляла 4 раза в неделю по 2 часа. Обследование проводили в два этапа: в зимнее и весенне-летнее время с обязательного письменного согласия юных спортсменов и их родителей.

В исходном состоянии $\mathrm{y}$ исследуемых регистрировали ЭКГ электрокардиографом «Полиспектр» («Нейрософт», Россия). Нагрузочное тестирование проводили на велоэргометре со ступенчато возрастающей (две ступени - 1 Вт/кг и 1,5 Вт/кг) физической нагрузкой (ФН). Период восстановления (ПВ) после выполнения каждой ступени составил три минуты.

В течение всего обследования непрерывно регистрировали ЧСС и артериальное давление (систолическое САД, диастолическое - ДАД) при помощи тонометра OMRON iq-142 (OMRON, Япония). С первой по третью минуты ПВ регистрировали ЭКГ в стандартных отведениях от конечностей.

Расчет критерия Шапиро-Уилка показал нормальное распределение полученных данных, поэтому анализ различий внутри группы проводили по tкритерию для связанных выборок. В статье результаты представлены в виде средней арифметической и стандартного отклонения $(\mathrm{M} \pm \mathrm{SD})$. Статистически значимыми считали различия при $\mathrm{p}<0.05$.

\section{РЕЗУЛЬТАТЫ \\ ИССЛЕДОВАНИЯ ОБСУЖДЕНИЕ}

И

ИX

Динамика

изменения

гемодинамических показателей и скорость их восстановления к исходным значениям на воздействие ФН косвенно характеризует функциональное состояние сердечно-сосудистой спортсменов [6].

$B$ зимний период при выполнении нагрузки разминочной и субмаксимальной мощности и ПВ у воркутинских спортсменов показатели ЧСС были статистически значимо выше, чем у сыктывкарских тхэквондистов. В исходном состоянии на пятой минуте первого и второго восстановления у тхэквондистов умеренной климатической зоны ЧСС составила $78 \pm 12$ уд/мин, $124 \pm 11$ уд/мин, $148 \pm 8$ уд/мин; у представителей арктических широт соответствующие значения показателей составили: $88 \pm 11$ уд/мин, $129 \pm 12$ уд/мин, $160 \pm 6$ уд/мин. $H a$ весенне-летнем этапе обследования прирост ЧСС у тхэквондистов Крайнего Севера при воздействии ФН был более значительным, в постнагрузочный восстановительный период показатели возвращались к исходным у всех спортсменов, существенно не различаясь между группами. У юных тхэквондистов г. Воркуты ЧСС в покое оставила $76 \pm 8$ уд/мин, достигая $113 \pm 11$ уд/мин при разминочной и $149 \pm 7$ уд/мин при субмаксимальной нагрузках; у детей г. Сыктывкара в соответствующие минуты обследования значения составили $89 \pm 4$ уд/мин, $125 \pm 12$ уд/мин, $159 \pm 8$ уд/мин.

Со стороны артериального давления у сыктывкарских детей реакция на нагрузку была нормотонического типа в оба сезона обследования, прирост давления при ФН был преимущественно за счет САД. ДАД практически не изменялось либо повышалось незначительно, не выявлен «бесконечный тон» или ступенчатое, скачкообразное его повышение в ПВ. В весенне-летний период САД и ДАД у сыктывкарских 
тХэквондистов в покое составил $100 \pm 4$ и $69 \pm 4$ мм рт.ст. соответственно, при измерении сразу после разминочной нагрузки достигнув $109 \pm 5$ и $69 \pm 4$ мм рт. ст.; после субмаксимальной нагрузки $116 \pm 5$ и $70 \pm 3$ мм рт. ст. Зимой у юных сыктывкарцев отметили незначительное увеличение артериального давления: САД и ДАД составило в покое $109 \pm 4$ и $72 \pm 3$ мм рт.ст., после первой нагрузки $-121 \pm 6$ и $76 \pm 4$ мм рт.ст., после субмаксимальной $127 \pm 6$ и $74 \pm 3$ мм рт.ст.

У юных воркутинцев в исходном состоянии, сразу после первой и второй нагрузки, САД и ДАД были статистически значимо выше, чем у детей умеренноконтинентальной климатической зоны, и составили в весенне-летний период: $115 \pm 3$ и $77 \pm 4$ мм рт.ст., $121 \pm 3$ и $75 \pm 3$ мм рт.ст., $128 \pm 4$ и $76 \pm 4$ мм рт.ст. (р<0.05). Зимой эти показатели составили: $102 \pm 4$ и $74 \pm 2$ мм рт.ст., $114 \pm 4$ и $79 \pm 3$ мм рт.ст., $118 \pm 4$ и $82 \pm 4$ мм рт.ст., характеризуя тем самым меньший прирост пульсового давления по сравнению с сыктывкарскими тхэквондистами $(\mathrm{p}<0.05)$.

Прирост пульсового давления при нагрузке указывает на адекватную реакцию сердечно-сосудистой системы на выполняемую работу. Повышенные показатели САД и ДАД у воркутинских тхэквондистов в весенне-летнее время по сравнению с сыктывкарскими указывают на более напряженную работу регуляторных механизмов кардиогемодинамики. Вероятно, это связано с сезонным уменьшением адаптационного резерва у детей арктической зоны, когда компенсаторные возможности организма к стрессвоздействиям после долгой зимы снижены максимально [5].

При анализе ЭКГ у всех обследованных юных спортсменов в исходном состоянии, при проведении велоэргометрии отметили синусовый ритм. На весенне-летнем этапе продолжительность Р-волны в покое у всех обследованных детей была в пределах поло-возрастной нормы [7] $(138 \pm 25$ и
$154 \pm 29$ мс у сыктыкарцев и воркутинцев соответственно), в зимнее время по сравнению с весенним отметили статистически значимое уменьшение длительности Р-зубца у воркутинских спортсменов $\quad(123 \pm 17 \quad$ мc). Продолжительность интервала PQ в весенне-летний период существенно не различалась у детей Сыктывкара (168 \pm 27 мс) и Воркуты $(187 \pm 29)$ при межгрупповом сравнении. При нагрузочном тестировании на третьей минуте восстановления у юных воркутинцев на весенне-летнем этапе длительность PQ интервала была значимо короче, чем у сыктывкарских тхэквондистов. Долговременное проживание в условиях северных широт приводит к обструкции верхних дыхательных путей при контакте с морозным воздухом, для жителей Крайнего Севера в холодное время года характерны гипервентиляция легких и обусловленное этим повышение среднего давления в легочных артериях, что отражается на ЭКГ изменением морфологии Р-волны и продолжительности PQ интервала [3]. У обследованных нами воркутинских спортсменов мы отметили схожую динамику изменения длительности Рволны.

Продолжительность деполяризации желудочков сердца (интервал QRS) у всех юных спортсменов находилась в пределах физиологической нормы (до 100 мс) $[7,8]$ и значимо не различалась в покое и при велоэргометрии ни в сезонной динамике у спортсменов одной широты, ни между показателями тхэквондистов разных климатогеографических зон. Функциональные нарушения миокарда отражаются на ЭКГ увеличением продолжительности QRS-комплекса при стресс-воздействиях [7, 8]. Стабильная продолжительность интервала QRS y обследованных детей является благоприятной характеристикой электрической активности сердца в период деполяризации желудочков сердца. 


\section{Длительность интервала QT} обследованных в исходном состоянии статистически значимо различалась и в зимнее, и в весенне-летнее время между показателями у детей Сыктывкара $(401 \pm 12$ мс и $404 \pm 16$ мс, соответственно) и Воркуты $(375 \pm 11$ мс и $377 \pm 7$ мс, зимой и в весенне-летний период, соответственно). С первой по третью минуты восстановления после ФН продолжительность QTинтервала сократилась у тхэквондистов из сравниваемых групп, но статистически значимых межгрупповых различий в разные сезоны года не выявлено. Длительность интервала QTc в покое у юных спортсменов из г. Сыктывкара составила $426 \pm 9$ мс зимой и $453 \pm 18$ мс. В весенне-летний период у представителей команды г. Воркуты составила $450 \pm 12$ мс в зимний период и $446 \pm 9$ в весенне-летний. При проведении нагрузочного тестирования с первой по третью минуты восстановления выявили статистически значимое различие продолжительности интервала QTc между юными представителями разных широт: $\mathrm{y}$ воркутинцев на каждой минуте восстановления он был значимо длиннее. Нормативной границей величины интервала QTc у детей принято считать 460 мс, превышение этого показателя при велоэргометрии дает основание для неблагоприятного прогноза функционального состояния спортсмена, поскольку удлинение интервала QTc косвенно отражает аритмогенность процессов восстановления возбудимости миокарда желудочков и повышение вероятности нарушений ритма сердца [7]. у обследованных нами юных тхэквондистов данный показатель практически у всех детей не превышал допустимую границу, что является физиологической нормой.

Согласно данным [9], у детей 7-15 лет по положению электрической оси сердца (ЭОС) наиболее часто встречаются: нормограмма (более чем у 50\% детей), полувертикальная ЭОС (около 40\%), правограмма у 4\% и горизонтальная ЭОС
(5-10\%). Это обусловлено анатомофизиологическими особенностями роста сердца и сосудов детей второго детского возраста [3]. При выполнении физической нагрузки происходит смещение ЭОС вправо из-за более глубоких дыхательных движений и опускании диафрагмы, происходящих вследствие гипервентиляции. В исходном состоянии у воркутинских и сыктывкарских спортсменов ЭОС была преимущественно полувертикальна, в период восстановления ЭОС смещалась вправо только у тхэквондистов г. Воркуты. Это можно объяснить более выраженной реакцией дыхательной системы на стрессвоздействие у детей северных широт, что было показано ранее в наших исследованиях [10].

\section{ЗАКЛЮЧЕНИЕ}

Исследование функционирования сердечно-сосудистой системы при выполнении физической нагрузки у юных спортсменов, проживающих и тренирующихся в разных климатогеографических поясах Республики Коми, выявило более неблагоприятную реакцию у детей арктической зоны по сравнению с таковой у детей умеренноконтинентального климата. Сравнительный анализ в контрастные сезоны года показал, что в период постнагрузочного восстановления более высокие значения гемодинамических параметров и временных характеристик электрической активности сердца у воркутинских тхэквондистов указывают на напряжение компенсаторных механизмов организма.

\section{Список литературы}

1. Арктическая энииклопедия. М.: «Паулсен». 2017; 1: 668.

2. Петров В.Н. Особенности влияния парциального градиента плотности кислорода в атмосферном воздухе на состояние здоровья населения, проживающего в арктической зоне РФ. Вестник Кольского научного иентра РАН. 2015; 3 (22): 82-92.

3. Гудков А. Б. Морфофункииональные особенности сердия и магистральных сосудов у детей школьного возраста. Архангельск: Изд-во. Северного 
государственного медицинского университета. 2011: 169

4. Солонин Ю.Г. Влияние широты проживания в условиях Севера на организм подростков. Физиология человека. 2012; 38(2): 107.

5. Евдокимов В.Г. Модулирующее влияние факторов Севера на кардиореспираторную систему человека в онтогенезе. Екатеринбург: УрО PAH. 2007: 258.

6. Белоцерковский

3.Б. Эргометрические $u$ кардиологические критерии физической работоспособности у спортсменов. М.: Советский спорт. 2005: 348.

7. Макаров Л.М. Нормативные nараметры ЭКГ у детей. М.: «МЕДПРАКТИКАM». 2018: 20.

8. Хомич М.М. Возрастные изменения временных показателей электрокардиограммы у детей. Bonpocbl современной педиатрии. 2006; 5(2): 17-19.

9. Осколкова М.К. ЭКГ у детей. М.: МЕД-пресс-информ. 2004: 352.

10. Шевелева Е.С. Кардиореспираторная система юных тхэквондистов Республики Коми в разные сезоны года. Известия Коми научного иентра. 2017; 3(31): 52-58.

11. Kuznetsova Z., Kuznetsov A., Mutaeva I., Khalikov G., Zakharova A., 2015. Athletes training based on a complex assessment of functional state. In Proceedings of the $3^{\text {rd }}$ International Congress on Sport Sciences Research and Technology support. SCITEPRESS. P. 156-160 (Scopus).

12. Kuznetsov A., Mutaeva I., Kuznetsova Z., 2017. Diagnostics of Functional State and Reserve Capacity of young Athletes' Organism. In Proceedings of the $5^{\text {th }}$ International Congress on Sport Sciences Research and Technology support. SCITEPRESS. P. 111-115 (Scopus).

References
1. Arkticheskaya enciklopediya [Arctic
encyclopedia]. Moscow: "Paulsen". 2017; 1:
668.
2. Petrov V.N. The peculiarities of partial oxygen density gradient influence in the air on population health state, in the arctic zone of the Russian Federation. Vestnik kol'skogo nauchnogo centra RAN [Kolsk scientific center of the Russian Academy of Sciences herald]. 2015; 3 (22): 82-92 [In Russ.].
3. Gudkov A. B. Morfofunkcional'nye osobennosti serdca I magistral'nyh sosudov u detej shkol'nogo vozrasta [Morphological-functional peculiarities of heart and great vessels among schoolchildren]. Arkhangelsk: North State Medical University publishing house. 2011: 169.

4. Solonin Y.G. The influence of the North latitude on an organism of teen-agers. Fiziologiya cheloveka [Physiology of a person]. 2012; 38(2): 107 [In Russ.].

5. Evdokimov V.G. Moduliryuchee vliyanie faktorov Severa na kardiorespiratornuyu sistemu heloveka $v$ ontogeneze [Modeling influence of North factors on cardiorespiratory system of a man in ontogenesis]. Ekaterinburg: Ural Department of the Russian Academy of Sciences. 2007: 258.

6. Belotserkovskiy Z.B. Ergometricheskie I kardiologicheskie kriterii fizicheskoj rabotosposobnosti u sportsmenov [Ergometric and cardiologic criteria of physical working capacity among athletes]. Moscow: Soviet sport. 2005: 348.

7. Makarov L.M. Normativnye parametry EKG $u$ detej [Normative parameters of ECG of children]. Moscow: «MEDPRAKTIKA -M». 2018: 20.

8. Khomich M.M. Age-related changes of time indices of children's electrocardiogram. Voprosy sovremennoy pediatrii [Questions of modern pediatrics]. 2006; 5(2): 17-19. [In Russ.].

9. Oskolkova M.K. EKG u detej [ECG of children]. Moscow: MED-press-inform. 2004: 352.

10. Sheveleva E.S. Cardiorespiratory system of young taekwondo athletes of the Republic of Komi in different seasons. Izvestiya Komi nauchnogo cetra [Komi scientific center news]. 2017; 3(31): 52-58 [In Russ.].

11. Kuznetsova Z., Kuznetsov A., Mutaeva I., Khalikov G., Zakharova A., 2015. Athletes training based on a complex assessment of functional state. In Proceedings of the $3^{\text {rd }}$ International Congress on Sport Sciences Research and Technology support. SCITEPRESS. P. 156-160 (Scopus).

12. Kuznetsov A., Mutaeva I., Kuznetsova Z., 2017. Diagnostics of Functional State and Reserve Capacity of young Athletes' Organism. In Proceedings of the $5^{\text {th }}$ International Congress on Sport Sciences Research and Technology support. SCITEPRESS. P. 111-115 (Scopus).

\section{Подано: 22.06.2018}

Шевелёва Елена Степановна - аспирант, младший научный сотрудник ФИЦ Коми НЦ, Федеральное государственное бюджетное учреждение науки Федеральный исследовательский иентр «Коми научный иентр Уральского отделения Российской академии наук» (ФИЦ Коми НЦ УрО РАН), 167982, Россия, Республика Коми, г. Сыктывкар, ул. Коммунистическая, дом 24, e-mail: bdr13@mail.ru 
Пантелеева Наталья Ивановна - кандидат биологических наук, научный сотрудник, Федеральное государственное бюджетное учреждение науки Федеральный исследовательский иентр «Коми научный иентр Уральского отделения Российской академии наук» (ФИЦ Коми НЦ УрО РАН), 167982, Россия, Республика Коми, г. Сыктывкар, ул. Коммунистическая, дом 24

Рощевская Ирина Михайловна - член-корреспондент РАН, профессор, главный научныій сотрудник, Федеральное государственное бюджетное учреждение науки Федеральный исследовательский иентр «Коми научный иентр Уральского отделения Российской академии наук» (ФИЦ Коми НЦ УрО РАН), 167982, Россия, г. Сыктывкар, ул. Коммунистическая, дом 24, Федеральное государственное бюджетное образовательное учреждение высшего образования «Сыктывкарский государственный университет им. Питирима Сорокина», 167982, Россия, Республика Коми, г. Сыктывкар, ул. Октябрьский npocnekm, d. 55, e-mail: compcard@mail.ru 